\title{
Quantitative genetics of growth and development in Populus. III. Phenotypic plasticity of crown structure and function
}

\author{
R. WU \& R. F. STETTLER* \\ College of Forest Resources, Box 352100, University of Washington, Seattle, WA 98195-2100, U.S.A.
}

\begin{abstract}
The whole-tree leaf area of a poplar derives from three different shoot types, current terminal, sylleptics and proleptics. The response of these architectural components to two sharply contrasting environments was examined in two replicated plantations containing a cloned interspecific hybrid pedigree of Populus trichocarpa and $P$. deltoides that included the original parents, two $F_{1}$ parents, and $375 \mathrm{~F}_{2}$ genotypes. In the warmer, sunnier, and better-watered environment of interior Boardman, Oregon, 2-year-old trees produced more, larger, and wider leaves, as well as more and longer branches, than in the cooler and more cloudy coastal conditions of Clatskanie, Oregon. Sylleptic branches were phenotypically more plastic than the other elements of the crown. Most trees produced significantly more and longer sylleptics in the near-optimal growth environment in Boardman than in the suboptimal environment of Clatskanie. In both environments, all crown traits displayed significant genotype effects in the $\mathrm{F}_{2}$ family, but for most traits, broad-sense heritabilities were statistically larger in Clatskanie (0.44-0.78) than Boardman (0.28-0.70). For all traits except for the number of sylleptics, the values of across-environment genetic correlations were significantly larger than zero but less than one, indicating that nonparallel responses of genotypes to environment had led to significant genotype $\times$ environment interactions, although some genetic basis was shared between the two environments. A nonsignificant genetic correlation of sylleptic number expressed in the two different environments suggests that the phenotypic plasticity of this trait is under strong genetic control. All architectural traits, except for branch and canopy traits of sylleptics, were correlated with growth more strongly in Clatskanie than Boardman. In both environments, contrary to observations in an earlier study, proleptic traits were better predictors of stem height and basal area growth than sylleptic traits.
\end{abstract}

Keywords: broad-sense heritability, genetic correlation, phenotypic plasticity, Populus, proleptics, sylleptics.

\section{Introduction}

The rapid growth of poplars (Populus L.) and their usefulness as a source of fibre, energy, and solidwood products has encouraged an expanding plantation culture worldwide, but especially in North America (Ranney et al., 1987; Abelson, 1991; Zsuffa et al., 1996). Typically practised on agricultural land, poplar culture involves the growth of selected hybrids in monoclonal stands under intensive culture for 6-12 years. The stands are then harvested, converted, and replaced by new selections. Increasing attention has been given to critical determinants

\footnotetext{
*Correspondence. E-mail: rstettle@u.washington.edu
}

of productivity in poplar and the methods by which they can be influenced through breeding, selection, and improved cultural techniques (reviewed in Ceulemans, 1990; Bisoffi \& Gullberg, 1996; Hinckley, 1996; Riemenschneider et al., 1996). One of the genetic approaches adopted in such studies has been to hybridize parents from species that differ in several components of productivity and to examine their segregating progenies in the $F_{1}, F_{2}$ and backcross $\left(B_{1}\right)$ generations. A suitable pair of species for this purpose are $P$. deltoides from the central and eastern US and $P$. trichocarpa from the Pacific coast, which differ in a wide array of morphological, anatomical and physiological traits (Hinckley et al., 1989). $F_{1}$ hybrids between the two are the most 
productive temperate-zone trees (ScarasciaMugnozza et al., 1997) and are widely planted in commercial plantations (Zsuffa et al., 1996). They are fertile and thus permit advanced-generation analysis (Stettler et al., 1988).

Quantitative-genetic and molecular studies of a three-generation hybrid pedigree of these two species have been conducted in a replicated plantation at Puyallup, WA, in the mesic environment of Puget Sound. They helped to shed light on the number of quantitative trait loci (QTLs) that control variation in 2-year tree height and diameter, and on their association with specific components of crown architecture (Wu \& Stettler, 1994; Bradshaw \& Stettler, 1995). Variation in the number and relative proportion of sylleptic vs. proleptic branches seemed especially pertinent to volume growth. Proleptic branches arise from axillary buds after an intervening period of dormancy, whereas sylleptic branches emerge from buds without such a winter dormancy (Hallé et al., 1978). Sylleptics in poplar have been shown to translocate a greater proportion of carbon to the stem than proleptics (Scarascia-Mugnozza, 1991). The dynamics in the relative importance of these two types of branches during development were further elucidated by 3rd-year data from a destructive sampling of the plantation (Wu \& Stettler, 1996).

To expand the study in both numbers and test locations, an enlarged material of the same $\mathrm{F}_{2}$ family (Fam. 331, $N=375$ ) and of a second, related family (Fam. 355, $N=225$ ), was planted in two contrasting environments, one maritime (Clatskanie, OR), the other continental (Boardman, OR). A companion paper summarized 2-year results from the analysis of stem growth traits in this material, documenting pronounced genetic variation in the response of genotypes to the two environments, i.e. strong genotype $\times$ environment interactions (Wu \& Stettler, 1997). For the present study we further investigated in Fam. 331 how variation in such components as leaves, branches and canopy architecture was associated with stem growth, and what degree of phenotypic plasticity was manifested by clonal replicates in the two environments. Phenotypic plasticity refers to the degree to which the phenotypic expression of a genotype varies under different environmental conditions (Sultan, 1987). Phenotypic plasticity could play an important role in trait evolution and plant breeding by buffering selection acting on genotypes (Bradshaw, 1965; Grant, 1985; Westcott, 1986). Plasticity also applies to character correlations that may be altered by the environment, in their sign as well as in their magnitude (Schlichting, 1989; Stearns et al., 1991). In this paper we address the following questions: (1) how did architectural components and their relationships within a crown vary in response to the two environments? and (2) how did environment and development interact to affect the genetic structure and genetic correlations between morphological traits and growth?

\section{Materials and methods}

\section{Plant pedigree}

Plant materials used in this study included a threegeneration pedigree derived from the cross of two morphologically distinct poplar species, Populus trichocarpa and $P$. deltoides, as described in $\mathrm{Wu} \&$ Stettler (1997). The P. trichocarpa clone 93-968, used as the female parent, is native to western Washington, whereas the male $P$. deltoides parent came from central Illinois. The $F_{2}$ family 331 , derived from the cross between two $F_{1}$ hybrid siblings, contains 375 genotypes. In spring 1993, rooted cuttings of this pedigree (including the original parents, $F_{1}$ parents and the $F_{2}$ family) were planted in two contrasting environments, one east of the Cascade Range in Boardman, OR (continental), the other west of the Cascades in the lower Columbia River Valley near Clatskanie, OR (maritime). Both field trials were laid out in a randomized complete block design with three (Clatskanie) or four clonal replicates (Boardman) and 2-tree plots at a spacing of $1.5 \times 3.0 \mathrm{~m}$. Further details on the two environments, the plantation designs and cultural regimes have been described (Wu \& Stettler, 1997). During the growing season the trees in Boardman experienced higher temperatures and solar radiation than those at Clatskanie. The Boardman plantation was drip-irrigated and fertilized, whereas the Clatskanie plantation depended upon natural precipitation and soil fertility.

\section{Trait measurements}

A number of characteristics, each describing a key architectural component of the poplar crown, were measured for each tree at the leaf, branch and canopy levels. In year 1 , two mature leaves at leaf plastochron index (LPI) of 8-12 (Larson \& Isebrands, 1971) on the stem were sampled to measure leaf length, leaf width, single-leaf area, leaf shape (i.e. leaf blade width/length) and petiole length. Leaf number on the stem was counted and further used to estimate total leaf area on the stem by combining it with the single-leaf area. In year 2, using the same 
sampling scheme, these measurements (except petiole length) were repeated for leaves from three different parts of the tree: current terminal (CT, but without leaf count), proleptics (PRO) and sylleptics (SYL) on the first-year stem increment. Branch number, single-branch length and second-year branch length increment were also measured. Measurements of leaf traits on branches and the last two branch traits were based on two average-sized branches for each branch type, PRO and SYL.

Height was measured annually, diameter at $3 \mathrm{~cm}$ above the ground in year 1 , and at the mid-point of the first-year height increment in years 2 and 3 . Basal areas and volume indices were calculated using diameter ${ }^{2} \times \pi / 4$ and height $\times$ diameter $^{2}$, respectively. The annual increments in height, basal area, and volume index were estimated by calculating the difference between the two successive years. The 3rd-year growth measurements were not made for the Boardman plantation because it was seriously damaged by a hailstorm during that growing season.

\section{Data analyses}

A standard method of carrying out a plasticity experiment is to grow various genotypes in a series of targeted environments and to monitor the variation in responses among these environments. The analysis of variance approach provides a means for detecting overall genetic variation in phenotypic plasticity, whereas linear or nonlinear approximations on environmental response are useful for evaluating reaction norms for individual genotypes. In this study, only the first approach was used because one of our main objectives was to determine the degree to which genotypes interact with environments in crown morphology and development.

The interactions between genotypes and plantation environments can be partitioned into two components resulting from heterogeneity of genetic variance and the lack of genetic correlation between environments (Wu \& Stettler, 1997). In this study, both environment-dependent genetic variances and across-environment genetic correlations were estimated. The two-way analysis of variance was employed to detect the effects of clone, replicate, and clone $\times$ replicate interaction in each environment in the $F_{2}$ family. Assuming both clonal and replicate effects to be random, variance components for the two main effects and an interaction effect were calculated by equating the mean squares with the expected mean squares derived from Type III sums of squares, PROC GLM (SAS Institute, 1988) and solving the ensuing equations. As discussed by
Wu \& Stettler (1996, 1997), the estimate of the genetic variance based on a single $\mathrm{F}_{2}$ family can be extended into a general case provided that all loci affecting a quantitative trait (QTL) are fixed for alternative alleles in the two original parents. This condition is likely to be met in our experiments, because the differences between the two original parental clones chosen for crossing are so great in the morphological traits studied that they can be assumed to be homozygous for QTL influencing these traits. Broad-sense heritabilities on a clonal mean basis were estimated for each environment (Wu \& Stettler, 1997) and their standard errors calculated using a modified version of the method suggested in Singh et al. (1993).

In addition, the formula for estimating the genetic correlation between performance of a trait in two environments was given in Wu \& Stettler (1997). The genetic correlations between leaf/branch and growth traits were estimated based on the two-way analysis of covariance model using similar procedures to estimate broad-sense heritabilities.

In all the above statistical analyses, the fourth replicate in Boardman was ignored because it had a different watering regime from the other replicates after the first year.

\section{Results}

\section{Phenotypic plasticity of canopy structure}

Trees developed different crown sizes and structures in the two environments, but differently in the three generations. In the warmer, sunnier, and betterwatered Boardman environment, trees generally showed greater growth (Wu \& Stettler, 1997) and produced more, larger and wider leaves, as well as more and longer branches, than in the cooler and more cloudy Clatskanie (see Figs 1-3). For leaf size, but not shape, the $F_{1}$ and $F_{2}$ hybrids were more sensitive to the two environments than the original parents (Fig. 1). The two branch types showed different phenotypic plasticities, with sylleptics being more plastic than proleptics in number and size (Fig. 2) as well as the leaf area they carried (Fig. 3). The $P$. trichocarpa parent showed a fairly stable proleptics:sylleptics proportion across the two environments, whereas the $P$. deltoides parent generated many more and longer sylleptics, combined with fewer proleptics, in Boardman than Clatskanie. In general, leaf and branch components of a canopy exhibited approximately normal distributions in the $\mathrm{F}_{2}$ family (e.g. Figs 1 and 2), but the distributions of canopy traits, such as cumulative leaf number and 

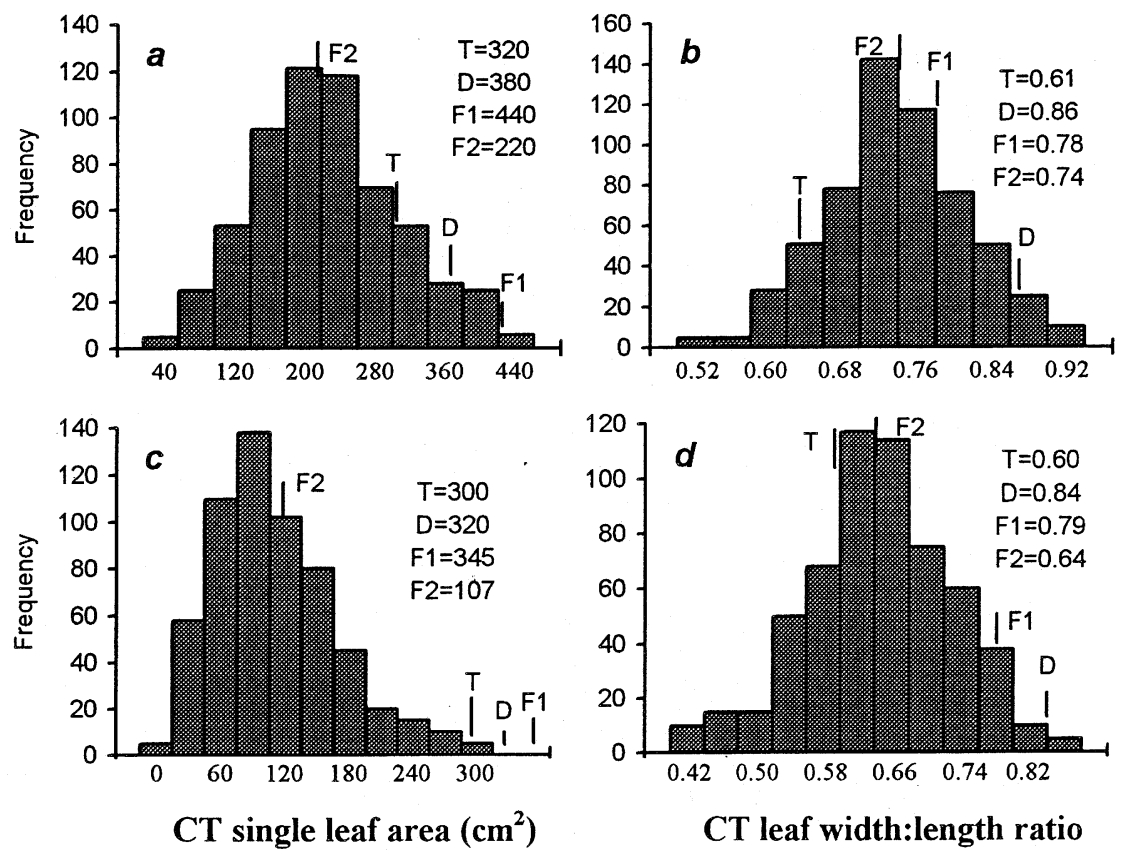

Fig. 1 Distribution of phenotypes for single-leaf area (a and c) and leaf width:length ratio ( $b$ and $d$ ) on the current terminal for 2-year-old trees in $F_{2}$ family 331 at Boardman (upper) and Clatskanie (lower). Means for the original parents (T, Populus trichocarpa; $\mathrm{D}$, P. deltoides), the $\mathrm{F}_{1}$ parents and the $\mathrm{F}_{2}$ family are indicated. area, were highly skewed towards the low values (Fig. 3).

\section{Environment-dependent genetic differentiation}

All crown traits displayed significant genotype effects in the $\mathrm{F}_{2}$ family in both environments, but for most traits, broad-sense heritabilities were statistically larger in Clatskanie $(0.44-0.78)$ than Boardman (0.28-0.70) (Table 1). Estimates of heritability also showed remarkable differences among traits, crown positions and years. In both years, leaf-size traits, such as length, width and area on the current terminal were under stronger genetic control than leaf shape. For these individual leaf traits, heritabilities were larger for sylleptics than proleptics in Boardman, but not in Clatskanie. By contrast, the reverse was true for heritabilities of branch and canopy traits in Clatskanie but not in Boardman; in Clatskanie heritabilities for all these traits were larger for proleptics than sylleptics.

Results from a two-way ANOVA indicated that the replicate effect was more frequently significant at a higher level in Boardman than Clatskanie (data not shown). In year 1, there was lower genetic differentiation in Boardman, thus explaining also the lower heritabilities there (Table 1). By year 2, however, genetic variance for leaf size traits on the current terminal had considerably gained in Boardman, in some cases even exceeding corresponding values from Clatskanie (Table 1).
For most traits, the values of across-environment genetic correlations were significantly larger than zero but less than one (Table 1), indicating that nonparallel response of genotypes to environment had led to significant genotype $\times$ environment interactions, although some genetic basis was shared between the two environments. Individual leaf traits had much larger across-environment genetic correlations $(0.50-0.72)$ than branch and canopy traits $(0.03-0.44)$; in year 2 , the correlation values followed the pattern of $C T>P R O>S Y L$ for all traits. The lowest correlation (0.03) was that of the number of sylleptics (Fig. 4). Although most genotypes showed increased syllepsis at Boardman, some (e.g. clone 1183) to a high degree, a few (e.g. clone 1120) showed a reduction, as did $P$. trichocarpa (Fig. 4).

\section{Environmental sensitivity of trait relationships}

Architectural components of a crown were genetically strongly correlated with stem growth, but with genetic correlations depending on environment, crown position and year (Tables 2 and 3 ). In year 1 , these correlations were larger at Clatskanie than Boardman (Table 2). At Boardman, the size, number and area of leaves on the stem were more tightly associated with height than basal area, whereas no such differences were observed at Clatskanie. First-year crown components were good predictors of 2nd- and 3rd-year stem volume incre-

(c) The Genetical Society of Great Britain, Heredity, 81, 299-310. 
ment, although there were some decreases in genetic correlation between the two kinds of traits, especially from years 1-2. In year 2, all architectural traits, except for branch and canopy traits on sylleptics, were correlated with growth more strongly in Clatskanie than Boardman (Table 3). The genetic correlations between 2nd-year architectural traits and growth were much a function of branch type. In both environments, leaf traits from the current terminal and proleptics were more closely correlated with height and basal area increments than those from sylleptics. For branch and canopy traits too, proleptics were generally better growth predictors than sylleptics, especially for basal area and volume
Fig. 2 Distribution of phenotypes for the number of proleptics (a and c) and of sylleptics (b and d), and the average branch length of proleptics (e and $g$ ) and of sylleptics (f and $h$ ) for 2-year-old trees in $\mathrm{F}_{2}$ family 331 at Boardman (upper) and Clatskanie (lower). Means for the original parents (T, Populus trichocarpa; $\mathrm{D}, P$. deltoides), the $\mathrm{F}_{1}$ parents and the $\mathrm{F}_{2}$ family are indicated.
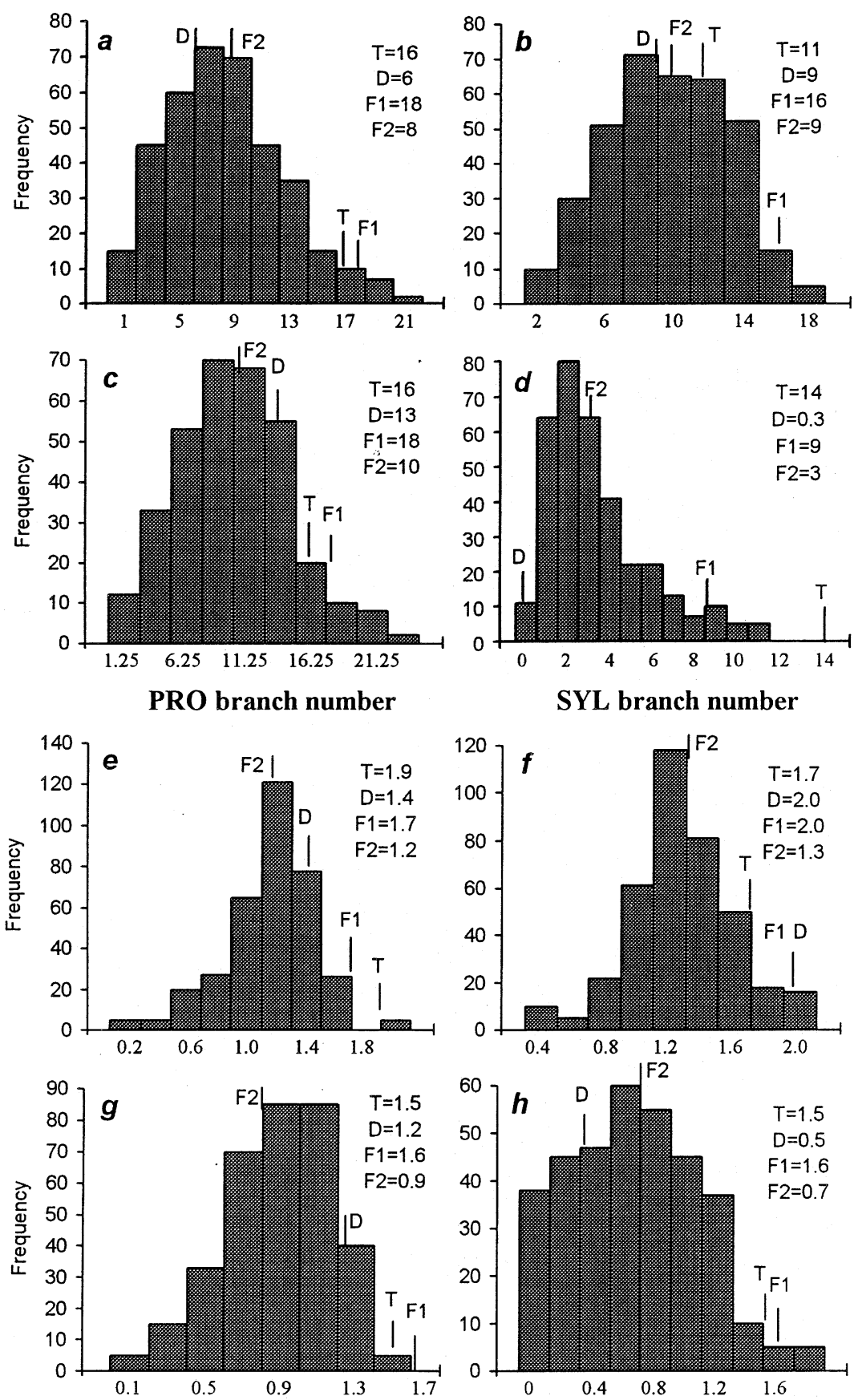

PRO average branch length (m)
SYL average branch length (m) 

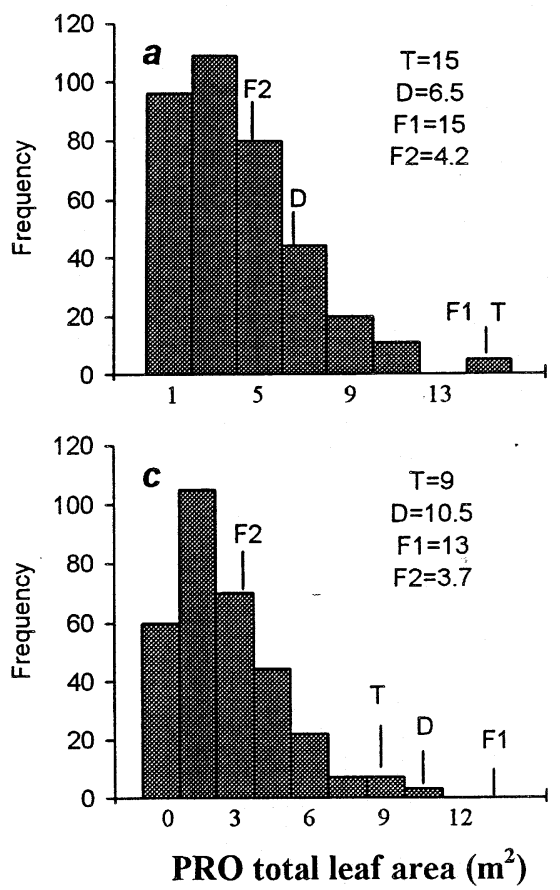
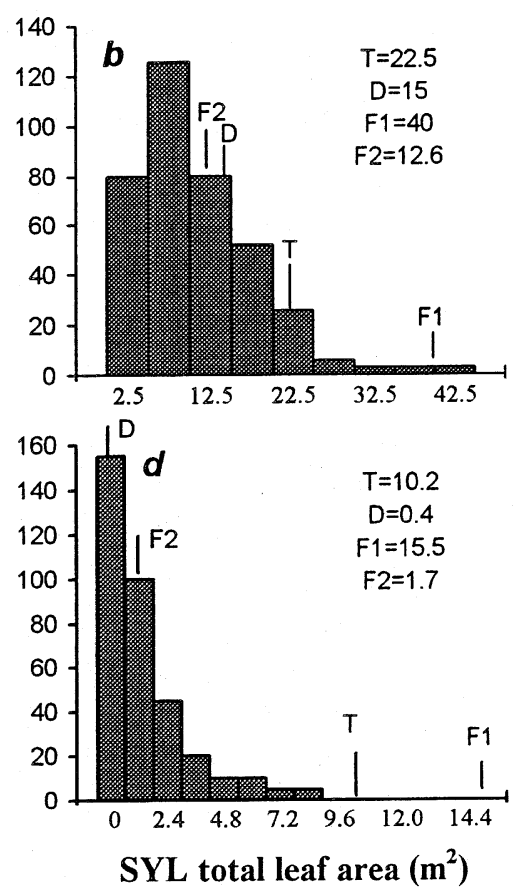

Fig. 3 Distribution of phenotypes for total leaf area on proleptics (a and c) and on sylleptics (b and d) for 2-yearold trees in $\mathrm{F}_{2}$ family 331 at Boardman (upper) and Clatskanie (lower). Means for the original parents ( $\mathrm{T}$, Populus trichocarpa; $\mathrm{D}$, P. deltoides), the $F_{1}$ parents and the $F_{2}$ family are indicated. growth. Observations at Clatskanie showed 2nd-year architectural traits to be useful in predicting volume increment in year 3 (Table 3 ).

Whereas genetic correlations describe the genetic association between two variables, the coefficient of regression can reflect the phenotypic impact of the independent on the dependent variable. As shown in Fig. 5, architectural traits always produced larger effects on stem volume growth in Boardman than Clatskanie (i.e. higher regression coefficients), although more genetic basis was shared between these two kinds of traits in Clatskanie than Boardman (Table 2). In neither environment was there a significant association between the numbers of sylleptics and proleptics (data not shown).

\section{Discussion}

\section{Plasticity of tree architecture}

This study has confirmed and amplified our earlier findings on growth patterns in the three-generation P. trichocarpa $\times P$. deltoides hybrid pedigree $(\mathrm{Wu} \&$ Stettler, 1996). The expansion of the $F_{2}$ family from 55 to 375 genotypes, and the exposure of the three generations to two contrasting environments, broadened the range of variation and revealed new levels of phenotypic plasticity in crown architecture in this material. As described in the first account of the two replicate plantations (Wu \& Stettler, 1997), all three generations displayed greater mean growth in the warm, high-radiation, and well-watered regime at Boardman than in the cooler coastal conditions at Clatskanie. The present study shows that this greater growth in Boardman was associated with a larger leaf area per tree, derived in part from more and larger leaves on all three shoot types: current terminal, proleptic and sylleptic branches, and in part from more numerous sylleptics. The mean increase in single-leaf area was most pronounced in the $\mathrm{F}_{1}$ and $\mathrm{F}_{2}$ hybrids (28\% and $106 \%$, respectively), and least in the $P$. trichocarpa parent $(7 \%)$. Leaf size in poplar is generally highly responsive to available light, water and nutrition, and typically varies even within a tree (reviewed in Ceulemans, 1990; Van Volkenburgh \& Taylor, 1996). The response measured in the P. trichocarpa clone seems unusually low; an earlier study with broader material from that species tested in both xeric and mesic environments gave leaf-size differences between sites averaging 50\% (Dunlap et al., 1995).

The main contributors to the increased leaf area in Boardman trees, however, were the sylleptics. Most trees produced significantly more and longer sylleptics in the near-optimal growth environment in Boardman than in the suboptimal environment of Clatskanie. In fact, the discrepancy in sylleptic leaf area between the two plantations would have been even greater, had the sylleptics on the second-year stem increment also been included in the estimates 
(field observations indicated a high year-to-year consistency in sylleptic production for most trees). By contrast, proleptic numbers and lengths showed only a minor upwards shift at Boardman. Sylleptic branching is less common in temperate than in tropical trees (Hallé et al., 1978) but prominent, e.g. in Alnus, Betula, Populus and Prunus, and its degree is dependent on genotype, environment and parentshoot vigour (reviewed in Hinckley et al., 1992). This is evident again in our results showing how the degree to which syllepsis was affected by the environment, varied by genotype. The wide difference between parental clones in sylleptic number at Clatskanie was smaller under Boardman conditions because of the strong upward response by $P$. deltoides, whereas the variation in the $F_{2}$ increased, transgressing the parental clones at that location. Members of the $F_{2}$ family varied greatly in their plasticity of syllepsis, some showing consistency between the two sites, others pronounced differ-

Table 1 Broad-sense heritabilities $\left(H^{2} \pm \mathrm{SE}\right)$, genetic variances $\left(V_{\mathrm{g}}\right)$, and genetic correlations $\left(r_{\mathrm{g}_{\mathrm{BC}}}\right)$ for leaf, branch and canopy traits between Boardman and Clatskanie in $\mathrm{F}_{2}$ family 331 of Populus

\begin{tabular}{|c|c|c|c|c|c|c|c|}
\hline \multirow[b]{2}{*}{ Trait } & \multicolumn{3}{|c|}{$H^{2} \pm \mathrm{SE}$} & \multicolumn{3}{|c|}{$V_{\mathrm{g}}$} & \multirow[b]{2}{*}{$r_{\mathrm{g}_{\mathrm{BC}}}$} \\
\hline & Boardman & & Clatskanie & Boardman & & Clatskanie & \\
\hline \multicolumn{8}{|l|}{ Year 1} \\
\hline \multicolumn{8}{|l|}{ Leaf } \\
\hline Length & $0.53 \pm 0.043$ & $<* * *$ & $0.73 \pm 0.035$ & 5.54 & $<* * *$ & 9.63 & 0.701 \\
\hline Width & $0.56 \pm 0.041$ & $<* * *$ & $0.70 \pm 0.032$ & 4.17 & $<* *$ & 5.53 & 0.722 \\
\hline Single area & $0.54 \pm 0.040$ & $<* * *$ & $0.66 \pm 0.036$ & 2247 & $<* *$ & 2950 & 0.714 \\
\hline Shape & $0.28 \pm 0.052$ & $<* * *$ & $0.44 \pm 0.046$ & 0.0118 & $<^{*}$ & 0.0121 & 0.493 \\
\hline Petiole length & $0.67 \pm 0.038$ & $<* * *$ & $0.75 \pm 0.033$ & 1.31 & $<^{*}$ & 1.90 & 0.716 \\
\hline \multicolumn{8}{|l|}{ Canopy } \\
\hline Leaf number & $0.48 \pm 0.049$ & $<* * *$ & $0.59 \pm 0.042$ & 66 & $\approx$ & 70 & 0.571 \\
\hline Total leaf area & $0.49 \pm 0.046$ & $<* * *$ & $0.63 \pm 0.042$ & 0.0696 & $\approx$ & 0.0568 & 0.703 \\
\hline \multicolumn{8}{|l|}{ Year 2} \\
\hline \multicolumn{8}{|l|}{ Leaf } \\
\hline Length CT & $0.70 \pm 0.034$ & $<*$ & $0.75 \pm 0.032$ & 8.74 & $<*$ & 9.37 & 0.692 \\
\hline PRO & $0.44 \pm 0.046$ & $<* * *$ & $0.61 \pm 0.034$ & 4.47 & $<^{*}$ & 5.01 & 0.618 \\
\hline SYL & $0.59 \pm 0.041$ & $<* *$ & $0.65 \pm 0.035$ & 2.96 & $<* *$ & 3.62 & 0.629 \\
\hline Width CT & $0.68 \pm 0.038$ & $<* *$ & $0.78 \pm 0.033$ & 6.48 & $\approx$ & 5.76 & 0.702 \\
\hline PRO & $0.42 \pm 0.051$ & $<* * *$ & $0.66 \pm 0.035$ & 2.96 & $\approx$ & 3.07 & 0.644 \\
\hline SYL & $0.52 \pm 0.047$ & $<* * *$ & $0.64 \pm 0.039$ & 1.80 & $\approx$ & 1.83 & 0.590 \\
\hline Single area $\mathrm{CT}$ & $0.67 \pm 0.036$ & $<^{*}$ & $0.73 \pm 0.034$ & 5545 & $>* * *$ & 3025 & 0.702 \\
\hline PRO & $0.39 \pm 0.054$ & $<* * *$ & $0.57 \pm 0.046$ & 1507 & $>* * *$ & 998 & 0.627 \\
\hline SYL & $0.47 \pm 0.043$ & $<* *$ & $0.58 \pm 0.045$ & 649 & $>* * *$ & 492 & 0.591 \\
\hline Shape CT & $0.53 \pm 0.041$ & $<*$ & $0.63 \pm 0.040$ & 0.0067 & $<*$ & 0.0086 & 0.687 \\
\hline PRO & $0.49 \pm 0.044$ & $<* * *$ & $0.66 \pm 0.039$ & 0.0063 & $<* * *$ & 0.0100 & 0.692 \\
\hline SYL & $0.53 \pm 0.043$ & $<* *$ & $0.63 \pm 0.039$ & 0.0064 & $<*$ & 0.0075 & 0.644 \\
\hline \multicolumn{8}{|l|}{ Branch } \\
\hline Number PRO & $0.48 \pm 0.047$ & $<* *$ & $0.60 \pm 0.040$ & 15.3 & $<*$ & 21.3 & 0.193 \\
\hline SYL & $0.47 \pm 0.049$ & $\approx$ & $0.50 \pm 0.043$ & 14.6 & $>* * *$ & 4.8 & 0.030 \\
\hline Single length PRO & $0.45 \pm 0.051$ & $<* * *$ & $0.76 \pm 0.037$ & 0.893 & $>* * *$ & 0.086 & 0.444 \\
\hline SYL & $0.50 \pm 0.050$ & $\approx$ & $0.53 \pm 0.047$ & 0.948 & $>* * *$ & 0.173 & 0.369 \\
\hline Branch incre. PRO & $0.49 \pm 0.053$ & $<* * *$ & $0.64 \pm 0.037$ & 32.7 & $\approx$ & 37.8 & 0.322 \\
\hline SYL & $0.47 \pm 0.054$ & $<* * *$ & $0.52 \pm 0.046$ & 640 & $>* * *$ & 76 & 0.281 \\
\hline \multicolumn{8}{|l|}{ Canopy } \\
\hline Leaf number PRO & $0.50 \pm 0.049$ & $<* * *$ & $0.60 \pm 0.033$ & 39966 & $<^{*}$ & 46792 & 0.357 \\
\hline SYL & $0.45 \pm 0.054$ & $<^{*}$ & $0.51 \pm 0.049$ & 786203 & $>* * *$ & 114364 & 0.288 \\
\hline Total leaf area PRO & $0.46 \pm 0.053$ & $<* *$ & $0.52 \pm 0.048$ & 9.78 & $>* * *$ & 6.68 & 0.424 \\
\hline SYL & $0.44 \pm 0.054$ & $\approx$ & $0.46 \pm 0.050$ & 75 & $>* * *$ & 4 & 0.314 \\
\hline
\end{tabular}

CT, current terminal; PRO, proleptic branches; SYL, sylleptic branches.

${ }^{*} P \leq 0.05,{ }^{* *} P \leq 0.01,{ }^{* * *} P \leq 0.001$.

(C) The Genetical Society of Great Britain, Heredity, 81, 299-310. 


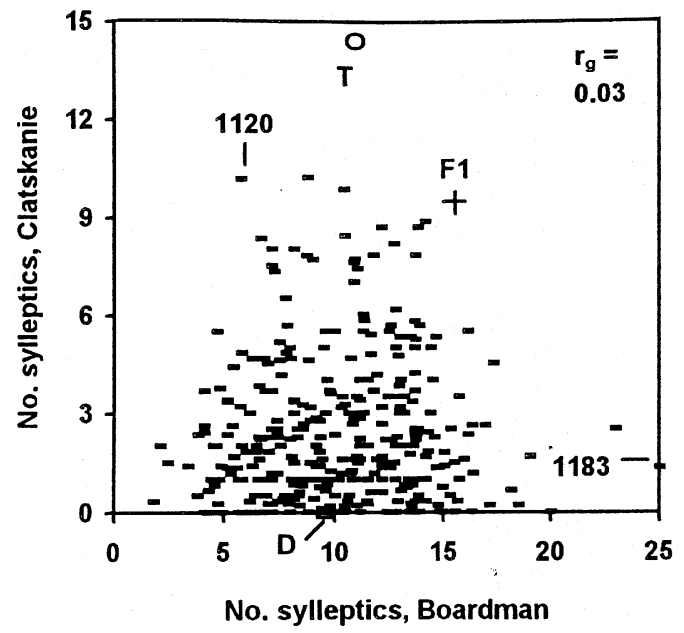

Fig. 4 The relationships between the numbers of sylleptics at Boardman vs. Clatskanie for the $\mathrm{F}_{2}$ family. Means for the original parents (T, Populus trichocarpa; $\mathrm{D}, P$. deltoides), the $\mathrm{F}_{1}$ parents and two contrasting $\mathrm{F}_{2}$ clones $(1120,1183)$ are indicated.

ences (Fig. 4). A few clones even had fewer sylleptics at Boardman than at Clatskanie, a reaction similar to that of their P. trichocarpa grandparent. Such contrasting $F_{2}$ recombinants may be of value in studies aimed at shedding light on the physiological mechanisms that regulate syllepsis; they also suggest that phenotypic plasticity, as a response of the

Table 2 Genetic correlations between 1st-year leaf and canopy traits vs. stem height (HT), basal area (BA) and volume increment $(\triangle \mathrm{VOL})$ at Boardman and Clatskanie in $\mathrm{F}_{2}$ family 331 of Populus

\begin{tabular}{|c|c|c|c|c|}
\hline \multirow[b]{2}{*}{ Trait } & \multicolumn{2}{|c|}{ Year 1} & \multirow{2}{*}{$\begin{array}{l}\text { Year } 2 \\
\Delta \text { VOL }\end{array}$} & \multirow{2}{*}{$\begin{array}{l}\text { Year } 3 \\
\Delta \text { VOL }\end{array}$} \\
\hline & HT & BA & & \\
\hline \multicolumn{5}{|l|}{ Leaf } \\
\hline Length Boardman & 0.66 & 0.55 & 0.48 & - \\
\hline Clatskanie & 0.78 & 0.76 & 0.69 & 0.63 \\
\hline Width Boardman & 0.69 & 0.59 & 0.48 & - \\
\hline Clatskanie & 0.82 & 0.79 & 0.68 & 0.62 \\
\hline Single area Boardman & 0.69 & 0.59 & 0.49 & - \\
\hline Clatskanie & 0.81 & 0.80 & 0.72 & 0.65 \\
\hline Shape Boardman & 0.28 & 0.24 & 0.17 & - \\
\hline Clatskanie & 0.30 & 0.27 & 0.18 & 0.15 \\
\hline Petiole length Boardma & 0.51 & 0.47 & 0.34 & - \\
\hline Clatskanie & 0.71 & 0.67 & 0.58 & 0.53 \\
\hline \multicolumn{5}{|l|}{ Canopy } \\
\hline Leaf number Boardman & 0.68 & 0.62 & 0.54 & - \\
\hline Clatskanie & 0.81 & 0.73 & 0.60 & 0.57 \\
\hline Total leaf area Boardman & 0.79 & 0.70 & 0.60 & - \\
\hline Clatskanie & 0.86 & 0.86 & 0.77 & 0.69 \\
\hline
\end{tabular}

organism to its environment, is under genetic control. A number of experiments have documented significant genetic variation in phenotypic plasticity for a wide range of species (Bradshaw, 1965; Sultan, 1987; Schlichting, 1989; Scheiner \& Lyman, 1991).

\section{Tree architecture and growth}

Regardless of the greater genetic variance in sylleptic traits at Boardman than at Clatskanie, genetic correlations between these traits and 2nd-year growth tended to be lower for that location than for Clatskanie. Evidently, the relative growth benefits from syllepsis were greater in the cooler coastal environment where sylleptics were a 'minimum factor'. And in both locations sylleptic traits showed lower genetic correlations with 2nd-year height, basal area, and volume growth than proleptic traits. However, at Boardman, these two kinds of traits showed a similar impact on volume growth, as described by regression coefficients (Fig. 5c,d). In an earlier study from a subset of this $F_{2}$ family, grown at a mesic location (Puyallup), genetic correlations of 2nd-year basal-area increment were found to be greater with sylleptic than proleptic leaf area $(\mathrm{Wu} \&$ Stettler, 1996), a result that had also served as the basis for a quantitative molecular model of the underlying genetics (Bradshaw \& Stettler, 1995). Changes in the correlation structure among traits in different environments have been observed in a number of other species (reviewed in Schlichting, 1986). Thomas et al. (1971) and Primack \& Antonovics (1981) suggested that morphological integration increases as the environment becomes more stressful. There is evidence that plants respond to low-resource environments by integrated physiological processes, often involving a decline in both growth rate and the rate of acquisition of all resources (Chapin, 1991). Growth in poplars is consistent with this concept, generally showing more repeatable architecture and allometries on low-nutrient sites and, because of indeterminate growth and opportunistic allocation, more irregular crown geometry on good sites (R. F. Stettler, pers. obs.). This also held for the present $F_{2}$ hybrid material which already at two years displayed a remarkable diversity of tree forms in the resourcerich environment of Boardman, in contrast to a more conservative range of variation at Clatskanie.

\section{Genetic control}

The consistently higher broad-sense heritability estimates for the Clatskanie plantation than for Board- 
man, in both years, point to the greater environmental homogeneity of the coastal site. Even though genetic variances in the second year were greater at Boardman, they were counterweighted by noticeable differences between replicates. The replicate effect in crown traits paralleled the one found earlier in growth traits which had accounted for $1-14 \%$, and replicate $\times$ genotype effect for $10-22 \%$, of the phenotypic variance (Wu \& Stettler, 1997). This heterogeneity among replicates was less the result of soil variation but primarily a consequence of differential wind impact across the plantation, and helped explain some of the more extreme tree forms encountered at Boardman. The heritability estimates of both plantations are lower by $10-20 \%$ than those estimated earlier for the same traits in a subset of this material grown at Puyallup ( $\mathrm{Wu} \&$ Stettler, 1996). We attribute this difference to a combination of two factors, the statistical tendency for overestimation of genetic variance in smaller $F_{2}$ families, and the greater site uniformity at the smaller Puyallup plantation. Our estimates are within the ranges of values previously reported for Populus (reviewed in Riemenschneider et al., 1996) but are considered specific to this pedigree and contingent on the assumption that all QTL are fixed for alternative alleles in the original parents.

\section{Summary and conclusions}

The study presented here and in a companion paper (Wu \& Stettler, 1997) captured the first two years of growth and development of a three-generation interspecific hybrid poplar pedigree exposed to two sharply contrasting environments. Two years are a third of the rotation length commonly used in poplar fibre farms in the Pacific North-west and are considered an adequate period to judge the growth potential of new hybrids in clonal evaluation trails (reviewed in Bisoffi \& Gullberg, 1996). Yet, two

Table 3 Genetic correlations between 2nd-year leaf, branch and canopy traits vs. stem height increment ( $\Delta$ HT), basal area increment $(\triangle \mathrm{BA})$ and volume increment $(\Delta \mathrm{VOL})$ at Boardman and Clatskanie in $\mathrm{F}_{2}$ family 331 of Populus

\begin{tabular}{|c|c|c|c|c|c|c|c|c|c|c|}
\hline \multirow[b]{3}{*}{ Trait } & \multicolumn{9}{|c|}{ Year 2} & \multirow{3}{*}{$\begin{array}{c}\text { Year } 3 \\
\Delta \text { VOL } \\
\text { Clat. }\end{array}$} \\
\hline & \multicolumn{3}{|c|}{$\Delta \mathrm{HT}$} & \multicolumn{3}{|c|}{$\Delta \mathrm{BA}$} & \multicolumn{3}{|c|}{$\Delta \mathrm{VOL}$} & \\
\hline & Board. & & Clat. & Board. & & Clat. & Board. & & Clat. & \\
\hline \multicolumn{11}{|l|}{ Leaf } \\
\hline Length CT & 0.64 & $\approx$ & 0.68 & 0.57 & $<$ & 0.65 & 0.57 & $<$ & 0.65 & 0.63 \\
\hline PRO & 0.63 & $<$ & 0.69 & 0.55 & $<$ & 0.68 & 0.55 & $<$ & 0.68 & 0.66 \\
\hline SYL & 0.47 & $>$ & 0.52 & 0.41 & $<$ & 0.52 & 0.40 & $<$ & 0.51 & 0.50 \\
\hline Width CT & 0.68 & $<$ & 0.73 & 0.64 & $\approx$ & 0.66 & 0.62 & $\approx$ & 0.66 & 0.64 \\
\hline PRO & 0.60 & $<$ & 0.74 & 0.54 & $<$ & 0.68 & 0.54 & $<$ & 0.68 & 0.66 \\
\hline SYL & 0.46 & $<$ & 0.57 & 0.43 & $<$ & 0.54 & 0.41 & $<$ & 0.53 & 0.53 \\
\hline Single area CT & 0.66 & $<$ & 0.71 & 0.62 & $\approx$ & 0.68 & 0.61 & $<$ & 0.69 & 0.67 \\
\hline PRO & 0.63 & $<$ & 0.73 & 0.57 & $<$ & 0.72 & 0.57 & $<$ & 0.73 & 0.70 \\
\hline SYL & 0.47 & $<$ & 0.56 & 0.44 & $<$ & 0.55 & 0.43 & $<$ & 0.54 & 0.54 \\
\hline Shape CT & 0.27 & $<$ & 0.36 & 0.28 & $\approx$ & 0.25 & 0.26 & $\approx$ & 0.24 & 0.21 \\
\hline PRO & 0.13 & $<$ & 0.37 & 0.14 & $<$ & 0.26 & 0.13 & $<$ & 0.25 & 0.23 \\
\hline SYL & 0.11 & $<$ & 0.27 & 0.13 & $\approx$ & 0.20 & 0.11 & $\approx$ & 0.19 & 0.18 \\
\hline \multicolumn{11}{|l|}{ Branch } \\
\hline Number PRO & 0.48 & $<$ & 0.62 & 0.60 & $\approx$ & 0.58 & 0.56 & $\approx$ & 0.58 & 0.55 \\
\hline SYL & 0.48 & $>$ & 0.37 & 0.40 & $<$ & 0.52 & 0.42 & $\approx$ & 0.46 & 0.44 \\
\hline Single length PRO & 0.68 & $<$ & 0.87 & 0.63 & $<$ & 0.77 & 0.61 & $<$ & 0.75 & 0.76 \\
\hline SYL & 0.64 & $>$ & 0.55 & 0.57 & $<$ & 0.62 & 0.55 & $\approx$ & 0.58 & 0.58 \\
\hline Branch incre. PRO & 0.58 & $<$ & 0.80 & 0.69 & $<$ & 0.77 & 0.66 & $<$ & 0.77 & 0.76 \\
\hline SYL & 0.56 & $>$ & 0.46 & 0.51 & $<$ & 0.59 & 0.51 & $\approx$ & 0.55 & 0.55 \\
\hline \multicolumn{11}{|l|}{ Canopy } \\
\hline Leaf number PRO & 0.53 & $<$ & 0.72 & 0.65 & $\approx$ & 0.71 & 0.62 & $<$ & 0.70 & 0.68 \\
\hline SYL & 0.57 & $>$ & 0.42 & 0.53 & $\approx$ & 0.55 & 0.54 & $\approx$ & 0.50 & 0.49 \\
\hline Total leaf area PRO & 0.61 & $<$ & 0.78 & 0.71 & $<$ & 0.80 & 0.69 & $<$ & 0.83 & 0.79 \\
\hline SYL & 0.60 & $>$ & 0.52 & 0.56 & $<$ & 0.65 & 0.57 & $\approx$ & 0.61 & 0.62 \\
\hline
\end{tabular}


years are the minimum period for the crown geometry to unfold (proleptic branches emerge only in the second growth season) and an inadequate span to anticipate the progressive effects of modular reiteration on the emergent tree architecture, especially after self-shading and competitive interactions set in under crown closure. Thus, 3rd- and 4th-year data would be critical for a better understanding of how crown/growth relationships in this material are affected by the two environments. Unfortunately, because of the severe hail damage inflicted on the Boardman plantation in the third growing season, valid comparisons between the two sites cannot be further extended. From the results obtained so far we offer the following conclusions and recommendations.

1 The expanded interspecific $F_{2}$ family presented a broad range of variation in crown architectures as a consequence of both variation within traits and recombination among trait variants, associated with genetic segregation and recombination. Few of the novel recombinants approached the growth performance of $F_{1}$ hybrids; none significantly exceeded it, perhaps in part because of inbreeding depression (Wu \& Stettler, 1997). A large fraction of suboptimal tree forms encountered also point to the
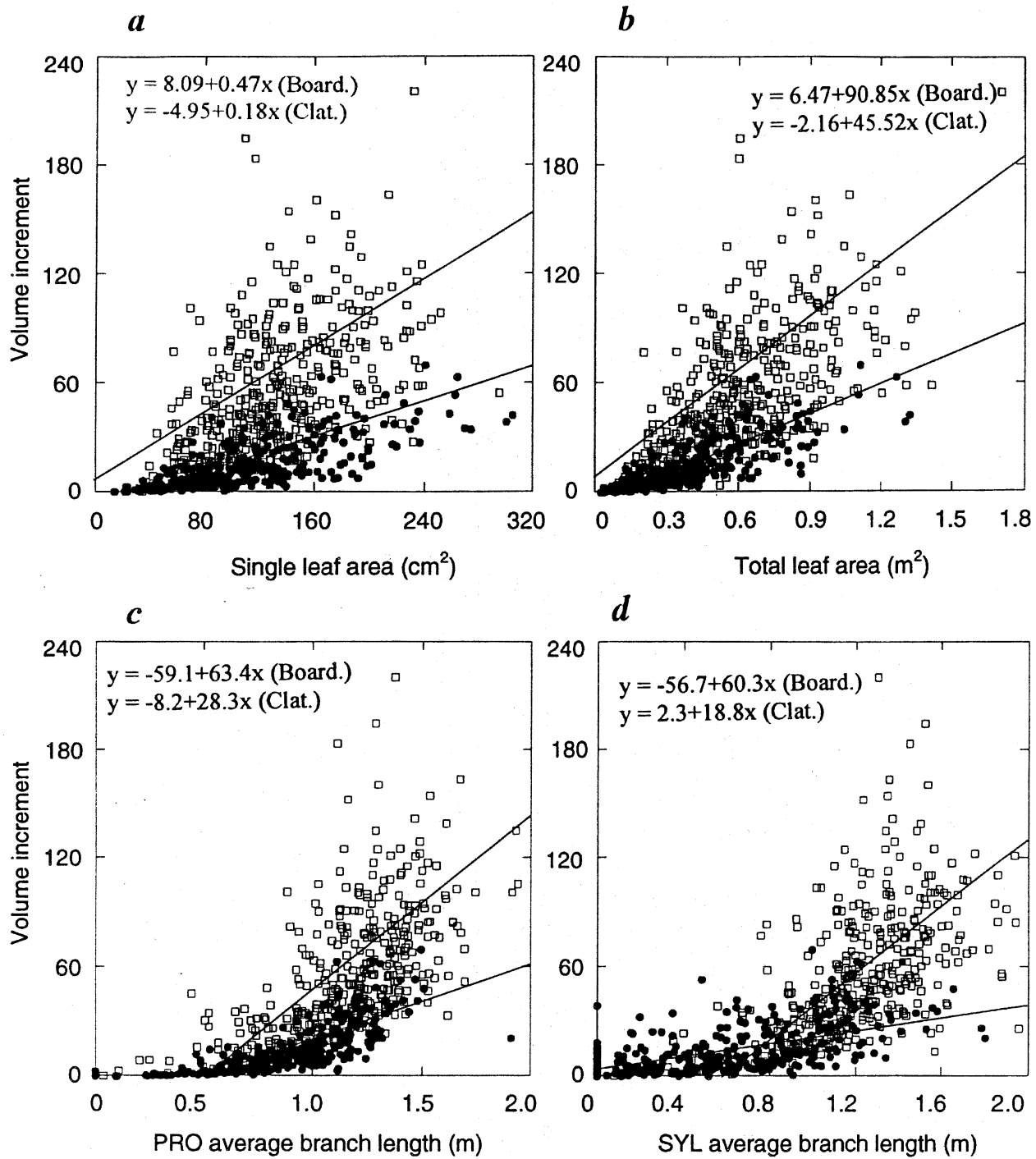

Fig. 5 The relationships of 2nd-year volume increment with 1st-year single leaf area (a) and total leaf area on the stem (b), and 2nd-year average branch length on proleptics (c) and sylleptics (d) in $\mathrm{F}_{2}$ family 331 of Populus at Boardman (open squares) and Clatskanie (solid circles). The regression equations of volume increment on component traits of crowns are given. 
likelihood of developmental disharmonies brought about by the disruption of coadapted genes through recombination (Futuyma, 1986, p. 194). Some of the more vigorous recombinants may offer promising and easy-to-replicate research material for a variety of morphological, physiological, and anatomical studies in tree architecture.

2 The strong response in most architectural features to the two environments documents once more the remarkable phenotypic plasticity of poplar. The experiment also revealed pronounced genotype $\times$ environment interactions, especially in important branch and canopy traits bearing on tree growth and quality. The practical implications are that in such contrasting environments it is advisable that (a) clonal selection and, in a broader sense, breeding, be conducted for each environment separately, as performance predictions from one site to another are unreliable; and (b) that cultural regimes too, especially spacing, be adapted to the unique response of selected clones to their stand conditions in each environment.

\section{Acknow ledgements}

We thank S. Wolpow and J. Whisler for data collection and management, Dr T. Bradshaw and an anonymous referee for helpful comments on this manuscript, and Boise Cascade Corporation and Fort James Corporation for plantation maintenance. This work has been supported through grants from the US Department of Energy (19X-43382C) and the Washington Technology Center (09-1022).

\section{References}

ABELSON, P. 1991. Improved yields of biomass. Science, 252, 1469.

BISOFFI, S. AND GUllberg, U. 1996. Poplar breeding and selection strategies. In: Stettler, R. F., Bradshaw, H. D., Jr., Heilman, P. E. and Hinckley, T. M. (eds) Biology of Populus and its Implications for Management and Conservation, pp. 139-158. NRC Research Press, National Research Council of Canada, Ottawa, ON.

BRADSHAw, A. D. 1965. Evolutionary significance of phenotypic plasticity in plants. Adv. Genet., 13, 115-155.

BRADSHAW, H. D., JR. AND STETTLER, R. F. 1995. Molecular genetics of growth and development in Populus. IV Mapping QTLs with large effects on growth, form, and phenology traits in a forest tree. Genetics, 139, 963-973. Ceulemans, R. 1990. Genetic Variation in Functional and Structural Productivity Determinants in Poplar. Thesis Publishers, Amsterdam.

CHAPIN, F. S., III. 1991. Integrated responses of plants to stress. BioScience, 41, 29-36.
DUNlaP, J. M., HEILMAN, P. E. AND STETTLER, R. F. 1995. Genetic variation and productivity of Populus trichocarpa and its hybrids. VIII. Leaf and crown morphology of native $P$. trichocarpa clones from four river valleys in Washington. Can. J. Forest Res., 25, 1710-1724.

FUTUYMA, D. J. 1986. Evolutionary Biology, 2nd edn. Sinauer Associates, Sunderland, MA.

Grant, v. 1985. The Evolutionary Process. Columbia University Press, New York.

HAllé, F., OLDEMAN, R. A. AND TOMLinson, P. B. 1978. Tropical Trees and Forests: An Architectural Analysis. Springer, Berlin.

HINCKLeY, T. M. 1996. Part II. Physiology of growth, productivity, and stress response: Overview. In: Stettler, R. F., Bradshaw, H. D., Jr., Heilman, P. E. and Hinckley, T. M. (eds) Biology of Populus and its Implications for Management and Conservation, pp. 277-281. NRC Research Press, National Research Council of Canada, Ottawa, ON.

HINCKLEY, T. M., CEULEMANS, R., DUNLAP, J. M., FIGLIOLA, A., HeIlMAN, P. E., ISEBRANDS, J. G. ET AL. 1989. Physiological, morphological and anatomical components of hybrid vigour in Populus. In: Kreeb, K. H., Richter, H. and Hinckley, T. M. (eds) Structural and Functional Responses to Environmental Stresses, pp. 199-217. SPB Academic Publishing, The Hague.

HINCKLEY, T. M., BRAATNE, J. H., CEULEMANS, R., CluM, P., DUNLAP, J. NEUMAN, D. ETAL. 1992. Growth dynamics and canopy structure. In: Mitchell, P., Ford-Robertson, J. B., Sennerby-Forsse, R. and Hinckley, T. M. (eds) Ecophysiology of Short Rotation Forest Crops, pp. 1-34. Elsevier Applied Science, London.

LARSON, P. R. AND ISEBRANDS, J. G. 1971. The plastochron index as applied to developmental studies on cottonwood. Can. J. Forest Res., 1, 1-11.

PRIMACK, R. B. AND ANTONOVICS, J. 1981. Experimental ecological genetics in Plantago. V. Components of seed yield in the ribwort plantain Plantago lanceolata L. Evolution, 35, 1069-1079.

RANNEY, J. W., WRIGHT, L. L. AND LAYTON, P. A. 1987. Hardwood energy crops: the technology of intensive culture. J. For., 85, 17-28.

RIEMENSCHNEIDER, D. E., STELZER, H. E. AND FOSTER, G. S. 1996. Quantitative genetics of poplars and poplar hybrids. In: Stettler, R. F., Bradshaw, H. D., Jr., Heilman, P. E. and Hinckley, T. M. (eds) Biology of Populus and its Implications for Management and Conservation, pp. 159-181. NRC Research Press, National Research Council of Canada, Ottawa, ON.

SAS Institute. 1988. SAS Users' Guide: Statistics. SAS Institute, Cary, NC.

SCARAscia-mugnozza, G. 1991. Physiological and Morphological Determinants of Yield in Intensively Cultured Poplar (Populus spp.). Ph.D. Thesis, University of Washington, Seattle, WA.

SCARASCIA-MUGNOZZA, G., CEULEMANS, R., HEILMAN, P. E., ISEBRANDS, J. G., STETTLER, R. F. AND HINCKLEY, T. M. 1997. Production physiology and morphology of Populus 
species and their hybrids grown under short rotation. II. Biomass components and harvest index of hybrid and parental species clones. Can. J. Forest Res., 27, 285-294.

SCHEINER, S. M. AND LYMAN, R. F. 1991. The genetics of phenotypic plasticity. I. Heritability. J. Evol. Biol., 2, 95-107.

SCHLICHTING, C. D. 1986. The evolution of phenotypic plasticity in plants. Ann. Rev. Ecol. Syst., 17, 667-693.

schlichting, C. D. 1989. Phenotypic integration and environmental change. BioScience, 39, 460-464.

Singh, M., CECCARElli, s. AND HAMBlin, J. 1993. Estimation of heritability from varietal trial data. Theor. Appl. Genet., 86, 437-441.

STEARns, S. C., DE LONG, G. AND NEWMAN, B. 1991. The effects of phenotypic plasticity on genetic correlations. Trends Ecol. Evol., 6, 122-126.

STETTLER, R. F., FENN, R. C., HEILMAN, P. E. AND STANTON, B. J. 1988. Populus trichocarpa $\times$ Populus deltoides hybrids for short rotation culture: variation patterns and 4-year field performance. Can. J. Forest Res., 18, $745-753$.

SUltAN, s. E. 1987. Evolutionary implications of phenotypic plasticity in plants. Evol. Biol., 21, 127-178.

THOMAS, R. L., GRAFIUS, J. E. AND HAHN, s. K. 1971. Stress: An analysis of its source and influence. Heredity, 26, 423-432.
VAN VOLKENBURGH, E. AND TAYLOR, G. 1996. Leaf growth physiology. In: Stettler, R. F., Bradshaw, H. D., Jr., Heilman, P. E. and Hinckley, T. M. (eds) Biology of Populus and its Implications for Management and Conservation, pp. 283-289. NRC Research Press, National Research Council of Canada, Ottawa, ON.

WESTCOTT, B. 1986. Some methods of analysing genotypeenvironment interaction. Heredity, 56, 243-253.

WU, R. AND STETTLER, R. F. 1994. Quantitative genetics of growth and development in Populus. I. A three-generation comparison of tree architecture during the first two years of growth. Theor. Appl. Genet., 88, 1046-1054.

WU, R. AND STETTLER, R. F. 1996. The genetic resolution of juvenile canopy structure and function in a three-generation pedigree of Populus. Trees, 11, 99-108.

WU, R. AND STETTLER, R. F. 1997. Quantitative genetics of growth and development in Populus. II. The partitioning of genotype $\times$ environment interaction in stem growth. Heredity, 78, 124-134.

ZSUFFA, L., GIORDANO, E., PRYOR, L. D. AND STETTLER, R. F. 1996. Trends in poplar culture: some global and regional perspectives. In: Stettler, R. F., Bradshaw, H. D., Jr., Heilman, P. E. and Hinckley, T. M. (eds) Biology of Populus and its Implications for Management and Conservation, pp. 515-539. NRC Research Press, National Research Council of Canada, Ottawa, ON. 